\title{
Entre Rupturas e Ajustes: O Ratio Studiorum e a Educação Brasileira
}

\section{Between Ruptures and Adjustments: The Ratio Studiorum and the Brazilian Education}

\section{Keila Soares Pardal ${ }^{*}$, Angelo Ferreira Monteiro ${ }^{2}$}

Como citar esse artigo. PARDAL, K.S.; MONTEIRO, A.F. Entre Rupturas E Ajustes: O Ratio Studiorum e a Educação Brasileira. Mosaico - Revista Multidisciplinar de Humanidades, Vassouras, v. 12 , n. 2, p. 25-33, mai./ ago. 2021.

Nota da Editora. Os artigos publicados na Revista Mosaico são de responsabilidade de seus autores. As informações neles contidas, bem como as opiniões emitidas, não representam pontos de vista da Universidade de Vassouras ou de suas Revistas.

\begin{abstract}
Resumo
Analisou-se os impactos causados pela Igreja Católica na Educação Brasileira com a vinda da Companhia de Jesus para o Brasil em 1549, na busca de saber quais estratégias usaram para a catequização, métodos educacionais que foram utilizados e os impactos na Educação Brasileira e como hoje no século XXI podemos perceber resquícios dessa educação. Alguns autores sinalizam algumas possibilidades de pesquisa como, a persistência de métodos na contemporaneidade, a mudança de cultura da sociedade brasileira e os dogmas católicos do período colonial, como também as diferenças de educação nos diferentes grupos sociais, buscando assim esclarecer algumas destas questões. Analisou-se ainda, as contribuições dos jesuítas na Educação Brasileira, sinalizando o primeiro contato com os nativos, e como ao longo desse tempo as rupturas nos métodos educacionais aplicados na Educação Brasileira podem ser observadas na sociedade atual. Como metodologia este trabalho teve a revisão de literatura e fontes como livros e artigos científicos, dissertações e teses. Este estudo demonstrou, o que a reforma Pombalina interferiu no avanço desta educação trazendo um retrocesso neste aspecto e como a Ratio Studiorum serviu de ferramenta para os educadores jesuítas.
\end{abstract}

Palavras-chave: colonização, Companhia de Jesus, educação, Reforma Pombalina

\begin{abstract}
It was analyzed the impacts caused by the Catholic Church in Brazilian Education with the coming of the Society of Jesus to Brazil in 1549, in search to knowing what strategies they used for catechization, the educational methods that were used and the impacts on Brazilian Education and how today in the 21st century we can perceive remnants of this education. Some authors point some research possibilities, such as the persistence of methods in contemporary times, the change in culture of Brazilian society and the Catholic dogmas of the colonial period, as well as the differences in education in the different social groups, thus seeking to clarify some of these issues. It was also analyzed the contributions of the Jesuits in Brazilian Education, signaling the first contact with the natives, and how over this time the ruptures in the educational methods applied in Brazilian Education can be observed in the current society. As methodology this work had the review of literature and sources such as books and scientific articles, dissertations and theses. This study demonstrated how the Pombaline reform interfered in the advancement of this education bringing a setback in this aspect and how the Ratio Studiorum served as a tool for Jesuit educators. As methodology this work had the review of literature and sources such as books and scientific articles, dissertations and theses. Keywords: colonization, Society of Jesus, education, Pombaline Reform
\end{abstract}

\section{Introdução}

Buscou-se analisar os impactos causados pela Igreja Católica na Educação Brasileira com a vinda da Companhia de Jesus para a América Portuguesa em 1549 , saber quais estratégias usaram para a catequização, os métodos educacionais que foram utilizados na época e como hoje podemos perceber fragmentos desta educação religiosa.

Levantou-se os impactos do método jesuítico na Educação Brasileira e como hoje no século XXI podese perceber resquícios daquele período, sinalizados por pesquisadores desta temática, que serão apresentados ao longo deste trabalho, sobre a persistência de métodos na contemporaneidade, a mudança de cultura da sociedade brasileira e os dogmas católicos do período colonial e ainda, as diferenças de educação nos diversos grupos sociais, buscando assim esclarecer estas questões, como as indicadas por Ricardo Pereira Calegari (2014), que apresenta uma ordem cronológica dos acontecimentos históricos referentes ao período da pesquisa entre outros.

Analisou-seainda, aimportânciae as contribuições dos jesuítas na Educação Brasileira mostrando como foi o primeiro contato dos jesuítas com os nativos através da catequização, observando-se como ao longo desse tempo se deram as rupturas nos métodos educacionais aplicados na Educação Brasileira e identificando na

\section{Afiliação dos autores}

${ }^{1}$ Graduada em Pedagogia pela Universidade de Vassouras.

${ }^{2}$ Doutorando em História pelo Programa de Pós-Graduação em História da Universidade do Vale do Rio dos Sinos - UNISINOS, Mestre em História Social e Graduado em História pela Universidade Severino Sombra - USS (atual Universidade de Vassouras), Professor Assistente III e Pesquisador da Universidade de Vassouras, Editor Executivo da Mosaico - Revista Multidisciplinar de Humanidades da Universidade de Vassouras e Responsável pelo Núcleo de Integração, Empreendedorismo Sociocultural e de Negócios da Universidade de Vassouras. Titular da cadeira nº 7 da Academia de Letras de Vassouras - ALV - Patrono Casimiro Cunha. Membro Colaborador do Instituto Histórico e Geográfico de Vassouras - IHGV. Patrono da Cadeira n 7 da Academia Juvenil de Letras de Vassouras - AJLV. 
sociedade atual a permanência da influência do ensino jesuíta.

Este trabalho teve como metodologia a revisão de literatura e utilizando-se os seguintes termos para pesquisa: colonização, Companhia de Jesus, educação, Reforma Pombalina, retirados de fontes como livros, artigos científicos, dissertações e teses.

A revisão de literatura teve como referencial teórico Almeida (2014) que destacou os pontos onde a educação jesuíta teve influência e onde percebe-se ainda na educação atual as permanências e assim fez-se o contraponto com outros autores como Shirley Sales et al. (2014) que analisou a repercussão da educação no período em que os jesuítas se encontravam à frente da Educação no Brasil. Tendo como objetivo analisar a importância e as contribuições dos jesuítas na educação brasileira.

\section{O iluminismo e a educação jesuítica}

O Iluminismo foi um movimento intelectual, filosófico e cultural que surgiu durante os séculos XVII e XVIII na Europa e defendia o uso da razão contra o antigo regime, pregando maior liberdade econômica e política. O iluminismo ou ilustração partia de ideias onde o ser humano era capaz de julgar e interpretar o mundo, se desvinculando da religiosidade, assim trazendo para a área educacional a tendência liberal e laica onde o indivíduo buscava sua autonomia, o que levou a ruptura com a tradição aristocrática do Antigo Regime. Com estas novas abordagens eles procuravam o progresso em diferentes direções, onde o passado não era mais visto como um modelo. Desta forma estes pensamentos influenciaram em diferentes áreas, como política, economia, questões sociais, na educação e religião. A partir das ideias iluministas a burguesia que ficava em segundo plano passou a ter mais controle e liberdade e com a Revolução Francesa (1789) defendiase o princípio de igualdade liberdade e fraternidade. (ARANHA 2006)

Pode-se afirmar que de certa forma o iluminismo tentava igualar as camadas sociais, assim com as revoluções burguesas que eclodiram no século XVIII e embasados nos pensamentos de Locke espalhadas no Novo Mundo e na Europa, resultou nos movimentos de emancipação bem sucedidos. (ARANHA 2006)

\footnotetext{
a força dos pensamentos modernos de filósofos empiristas como Locke, Hume e Bacon que defendiam a ideia de se buscar nas ciências da natureza o caminho seguro para se alcançar o progresso científico ganhavam cada vez mais a simpatia do legisladorportuguês, quevia nessa nova concepçãodefilosofia e de ciência uma maneira de projetar o Estado português rumo ao progresso e a ocupar o seu lugar de glória junto as demais nações europeias. (SANTOS FILHO et al. 2015, p.7)
}

Para Falcon (1994, p. 63) "a pedagogia iluminista envolvia duas ordens de indagações, que foram assunto dos políticos e dos 'filósofos' do setecentos: a questão da natureza do processo educativo e a questão da reforma e difusão das instituições educacionais" e defende que o

\footnotetext{
Fator-chave do progresso da razão, a pedagogia era para os iluministas o único caminho racionalmente possível no sentido da igualdade. Só ela poderia propiciar a eliminação, no futuro, do abismo que separava os espíritos bempensantes, moralmente bem-formados e socialmente bemeducados, da plebe ignorante, supersticiosa, inclinada aos maus costumes e mal-educada. (FALCON, 1994, p. 62-63)
}

Assim esta pesquisa analisou a educação na colônia portuguesa na América, a partir da chegada da Companhia de Jesus na América Portuguesa em 1549, liderada pelo padre Manoel da Nóbrega, sendo o primeiro modelo de educação na então colônia do Império Português, a princípio não com um caráter formador de indivíduo e sim de recrutamento de fiéis com um valor missionário à educação. "O projeto de colonização adotado pelo jesuíta Manoel da Nóbrega era centrado na importância do papel do colonizador, no Novo Mundo, como sendo aquele que levaria a civilização para os nativos" (LEITE, 1945 apud SÁ; COELHO, 2013, p. 6).

De acordo com Calegari (2014) a Companhia de Jesus na verdade foi criada em 1534, e a partir do século XVI teve como objetivo conter as reformas protestantes que estavam ocorrendo desde sua chegada até expulsão em 1759. Porém Casimiro (2006, p. 1) ressalta que "Devemos ter em mente que, além dos Jesuítas, também em outras ordens religiosas, mormente os franciscanos [...], os carmelitas, [...] dentre outras, também participaram da evangelização em missões".

A educação praticada pelos jesuítas contribuía à Coroa, de controle da população e de conformação dos índios quanto às retiradas e exploração de recursos da colônia brasileira. Através da proximidade pacífica dos jesuítas à população local, conseguia-se a colaboração de trabalho explorativo às terras sob um "pano" educacional. (CALEGARI, 2014, p. 9).

Alguns desafios enfrentados pelos jesuítas foram às línguas nativas dos povos indígenas que já habitavam na América Portuguesa, porém alguns destes primeiros padres estavam familiarizados com o estudo gramatical graças as Constituições, parte IV, escritas pelo próprio Sto. Inácio e em vigor desde 1552, que fazia algumas recomendações, e enfatizava a importância de conseguir compreender novas línguas e de outros povos, então por mais que fosse um desafio os padres jesuítas estavam preparados para uma abordagem para com os nativos (ROSA, 1995). Esta autora também destaca que, uma estratégia usada para melhor captação da língua era o ensinamento das crianças onde eles conseguiam ter uma melhor resposta. Também é relatado que alguns padres 
que já estavam familiarizados com o estudo gramatical e buscavam reduzir a LG (Língua Geral) à escrita, assim conseguiriam conviver com os nativos, e novamente se voltavam para o ensino das crianças, buscando obter melhores resultados.

O ensino introduzido pela Igreja teve muita importância e influência para o que chamamos hoje de Educação, uma vez que podemos considerar que eles foram um dos primeiros que de fato deram início às instituições de ensino e qualidade na colônia, acrescentando Leilson Oliveira et al. (2018, p. 628) que afirma "A Companhia de Jesus foi fundada por Santo Inácio de Loyola, em 1552, seu objetivo era desenvolver regras disciplinares para a vida religiosa e, sobretudo, para missões de evangelização". A partir daí podemos observar que mesmos estas regras possuíam em sua base, algo que era trabalhado e testado antes de ser aplicado, obtendo-se uma melhor eficiência em seus resultados. Segundo Calegari (2014), Ignácio de Loyola é um dos principais nomes citados na história dos jesuítas onde agregou grande importância em seus projetos, uma vez que era o fundador desta ordem religiosa, na manutenção de instituições educacionais, que ultrapassaram os séculos e que permanecem até a atualidade.

A educação jesuíta era voltada para a catequização dos indígenas, e visava mais as condutas do que de fato a aprendizagem pedagógica, buscavam estimular e tentar aproximá-los dos padrões considerados da civilização. (CALEGARI, 2014)

Observando estas afirmações percebe-se quais as primeiras intenções dos jesuítas, que na verdade não era só educação que visavam, mas também uma forma de contrapor as mudanças protestantes que estavam acontecendo em Portugal, que iriam afetar de modo negativo à Igreja, perdendo fiéis e poder. Mesmo assim, eles foram os primeiros a dar início à educação formal na América Portuguesa, contemplando de fato questões importantes mesmo que separadamente, de acordo com as camadas sociais, fazendo uso de outros artifícios como se basear na figura da família, sendo eles que iriam determinar o futuro de seus filhos e tomariam decisões sobre a sua educação e estudos. (RIBEIRO, 1993)

Dando-nos informações dos primeiros passos dos jesuítas no Brasil, Klein (2016) acrescenta como os jesuítas deram início as suas construções.

Aos 15 dias do primeiro desembarque, na Bahia, enquanto os portugueses iam construindo a cidade de Salvador, ao lado do Arraial do Pereira, os jesuítas colocavam em funcionamento a primeira instituição educativa em solo brasileiro, que construíram por suas mãos, indo ao mato buscar a madeira e fazendo as taipas. (KLEIN, 2016, p. 2)

Nóbrega, que liderou os primeiros missionários para a costa brasileira escreveu em sua primeira carta ao Provincial, em Portugal, ao afirmar que esta terra é nossa empresa. Os jesuítas entendiam a sua missão evangelizadora numa dupla dimensão, de catequese e instrução, que se alternavam e reforçavam no currículo escolar. Considerando muito difícil arrancar os índios adultos de costumes inveterados como a poligamia, o alcoolismo e a antropofagia, desde cedo os jesuítas concentraram os seus esforços educativos no segmento das crianças: curumins, mestiços ou mamelucos, e filhos dos portugueses adventícios (KLEIN, 2016).

Os jesuítas dessa forma faziam a distinção do ensino de acordo com as camadas sociais onde os filhos dos colonos tinham um ensino diferenciado

Nesse contexto social, a instrução, a educação escolarizada,
só podia ser conveniente e interessar a camada dirigente [...],
que seguindo ao modelo de colonização adotada, deveria
servir a uma articulação entre os interesses metropolitanos e
as atividades coloniais. (SHIRLEY SILVA et al., 2014, p. 3)

Desta forma privilegiavam a nobreza e ao ensino aos indígenas, havendo entre estes dois grupos distinção de saberes.

O ensino jesuítico era dividido entre a catequese e o ensino de humanidades. Aos índios era ensinado a ler e escrever, mas, também os ensinamentos católicos e todos esses ensinamentos eram baseados em livros bíblicos com a intenção de aculturá-los. (SHIRLEY SILVA et al., 2014, p. 3).

Segundo Leilson Oliveira et al. (2018) o método de ensino dos jesuítas composto de suas respectivas regras era conhecido como Ratio Studiorum onde se encontrava os princípios a serem seguidos e uma orientação pedagógica.

O Ratio Studiorum que era uma abreviação de Ratio atque Institutio Studiorum Societatis Iesu possuía 467 regras e passou por algumas versões até ser editada e promulgada em 1599. "O Ratio Studiorum não discute princípios educacionais nem expõe sistemas; sendo um Programa de Estudos formado por uma coleção de regras positivas e uma série de prescrições práticas e minuciosas", conforme Leilson Oliveira et al. (2018, p. 629). O que pode-se comparar com a Lei de Diretrizes e Bases da Educação - LDB (BRASIL, 1996) onde se encontra como no Ratio Studiorum, definições e regulamentações sobre a organização da educação.

Vito e Melo (2015, p. 272) acrescentam ainda outra similaridade entre ambos onde coloca que "a predominância ao ensino pela fé cristã da ordem jesuítica era a viga norteadora do método do Ratio Studiorum. Com isso, observam-se indícios similares na LDBEN ${ }^{1}$, considerando que o ensino religioso permeou a história da educação brasileira". Baseado nestes comparativos Leilson Oliveira et al. (2018) também acrescenta uma nova comparação

O Ratio Studiorum foi um instrumento norteador para a consolidação da Educação Jesuítica. Como sabemos da 
influência direta na construção de uma Educação Brasileira, não é surpresa encontrarmos elementos desse plano nos instrumentos atuais. Sabemos dos inúmeros documentos norteadores, por isso será feito um comparativo do Plano Institucional dos Jesuítas que serviram de parâmetros para os colégios da época, com um instrumento que hoje serve para suprir essas mesmas necessidades, o Projeto Político Pedagógico-PPP.(LEILSON OLIVEIRAet al.2018,p. 633)

"Os jesuítas eram extremamente rigorosos na seleção dos professores, onde só era permitido lecionar a partir dos 30 anos. Eles investiam muito no preparo dos mesmos" (SHIRLEY SILVA et al., 2014, p. 5). O que chama atenção para a importância que eles davam para educação e como a capacitação dos profissionais que ficariam responsáveis por lecionar e compor as escolas católicas, era a obrigatoriedade de formação e qualificação.

Com todas as estratégias adotadas para os ensinamentos na colônia, os jesuítas ganharam a confiança dos índios o que resultou na oposição da Coroa Portuguesa em relação aos mesmos, a influência jesuítica foi tão forte que acabaram obtendo mais poder tanto social quanto econômico que a própria Coroa portuguesa. (SHIRLEY SILVA et. al., 2014, p. 5).

A partir desta situação, o Marquês de Pombal ordenou que acabassem com todas as escolas jesuítas e que as destruíssem, causando um grande impacto na educação. "O ensino pode-se considerar semelhante ao dos jesuítas, porém, destacam-se algumas mudanças: as aulas eram avulsas, divididas e particulares (pagas) e o principal interesse do Marquês de Pombal era exercer controle sobre a colônia." (SHIRLEY SILVA et al., 2014, p. 5). Sendo assim a educação passou a não ser tão valorizada e contemplava apenas interesses e não necessidades, tendo uma recaída na educação e uma desvalorização do aluno.

Em 1759, as reformas realizadas por Sebastião José de Carvalho e Mello, o Marquês de Pombal, primeiroministro de Portugal de 1750 a 1777, vão extinguir o único "sistema" de educação do Vice-Reinado do Brasil com a expulsão da Companhia de Jesus. (OLIVEIRA, 2004, p. 2)

Trazendo à Educação do Brasil uma nova realidade, onde avanços que foram realizados pelos jesuítas foram desfeitos causando uma precariedade no ensino. No entanto, de acordo com Hilsdorf (2003) todas estas mudanças estavam embasadas de pensamentos do Absolutismo Ilustrado, que já estava sendo implantado em Portugal.

Para entendermos o conceito de Absolutismo Ilustrado vamos nos apoiar nas obras de Francisco José C. Falcon. Segundo este autor o regime do Absolutismo Ilustrado pode ser visto como o encontro de uma política e uma economia (a absolutista) com uma cultura (a das Luzes), definindo em relação ao Estado Absolutista Clássico do Antigo Regime um novo modelo, o Estado Absolutista
Ilustrado do século XVIII. (HILSDORF, 2003, p. 16)

Assim como consequência dava ênfase em aplicar as Luzes na vida social, política e cultural, que já estavam ocorrendo em Portugal para serem aplicadas na América Portuguesa, e como sendo o objetivo de Pombal fazer de "a substituição do "Estado da espada e da cruz" do século XVI, [..], e manter sob controle o "Estado da indústria e do comércio", dominado pela burguesia mercantil desde os meados do século XVIII" onde mostra esta nova visão. (HILSDORF, 2003, p. 17).

Shirley Silva et al. (2014) diz que "Ainda contrastando com os jesuítas, o Marquês propunha agregar ao ensino de humanidades, um ensino voltado para a formação de comerciantes e não intelectuais". Outro aspecto que se destaca era a falta de formação dos professores onde não eram capacitados e nem preparados, diferente dos professores jesuítas, assim tornando o ensino frágil, o que levaria mais tarde a acarretar uma série de problemas referente à educação. Oliveira (2004, p. 3) acrescenta ainda que com o Estado à frente da educação, pela primeira vez, surgiram grandes problemas na educação, uma vez que os mestres eram leigos em suas aulas régias, então recémcriadas e se mostravam incapazes de conseguir assimilar toda a modernidade em que se baseava a iniciativa pombalina.

De acordo com Shirley Silva et al. (2014, p. 6)

O momento educacional promovido pelo Marquês de Pombal foi considerado trágico, onde ele eliminou o sistema criado pelos jesuítas e trouxe grande retrocesso para a educação até então. Apesar de ter tentado organizar um sistema nacional pela primeira vez, o caos instalado pela expulsão dos jesuítas, foi considerável. (SILVA et al., 2014, p. 6)

Porém, vale ressaltar que mesmo que a proposta de Pombal tenha sido falha, por traz tinham intensões de melhorias para o Brasil, ao propor um novo patamar em busca da modernidade e também com fins para a melhoria do comércio, a partir da visão pragmática iluminista.

O período compreendido pela administração de D. João VI (1808-1821) e a transferência da corte portuguesa para o Brasil é também denominada por fase Joanina.

De acordo com Boaventura (2009, p. 129) "Com a desorganização do sistema de ensino pela expulsão dos jesuítas, a educação colonial veio a tomar novos rumos com a vinda da família real portuguesa." E com isso pode-se observar que com a chegada de D. João VI ao Brasil, mudanças no ensino foram notórias, destacando também no campo cultural como Imprensa Régia (1808), A biblioteca (1810), Jardim Botânico do Rio (1810), Museu Real (1818), depois Museu Nacional, Missão cultural francesa (1816), Academia 
Real da Marinha (1808) e Academia Real Militar (1810), Cursos médico-cirúrgicos e diversos cursos avulsos de economia, química e agricultura, também na Bahia e no Rio. Assim Aranha (2006), os destaca como relevantes por serem os primeiros centros de educação e cultura do Brasil, foi com D. João VI que também passamos para a secularização do Ensino Público.

De modo geral, podemos dizer que no século XIX ainda não havia uma política de educação sistemática e planejada. As mudançastendiamaresolverproblemasimediatos, semencarálos como um todo. Quando a família real chegou ao Brasil, existiam as aulas régias do tempo de Pombal, o que obrigou o rei a criar escolas, sobretudo superiores, a fim de atender às necessidades do momento. (ARANHA, 2006, p. 376)

Assim Shigunov Neto (2015) destaca outros acontecimentos importantes desta época. A partir da chegada de Dom João VI é abolido o sistema colonial de restrição de comércio, desta forma, permitindo a entrada de produtos estrangeiros na colônia assim como exportação de seus produtos, expandindo seu comércio. Saindo da Bahia, onde foi sua primeira parada, partiu para o Rio de Janeiro, onde viu a necessidade de criar e expandir e que também já se encontrava uma parte da corte portuguesa, assim acrescentando "Era necessário criar condições e instituições (repartições públicas, os tribunais, o aparato policial, a justiça, os órgãos administrativos) semelhantes às existentes em Lisboa para o funcionamento do 'novo Estado'." (SHIGUNOV NETO, 2015, p. 66)

Com a instalação da Coroa Portuguesa, sendo a cidade de São Sebastião, atual Rio de Janeiro, que passou a ser a capital administrativa, tinha uma população composta em sua maioria por escravos e pequenos comerciantes e possuindo mais de $50 \mathrm{mil}$ habitantes. Assim o Brasil passa a ser sede do Reino Português. A família real trouxe mudanças notórias na colônia em diferentes aspectos, propõe novos padrões, culturas diferentes, transformando a sociedade colonial e implantando melhorias nas lavouras e indústrias. "D. João VI criou algumas poucas escolas superiores; outras já existentes desenvolveram-se, com o intuito de suprir as carências de mão de obra qualificada para os serviços públicos criados pelo recém-criado Governo." (SHIGUNOV NETO, 2015, p. 68)

Desta forma os cursos superiores existentes e criados nesse período tinham como intuito a formação exclusiva do quadro burocrático, para o novo Estado Nacional.

Apesar de todas as mudanças e melhorias proporcionadas pela chegada da família real, vale lembrar "que essa prosperidade não beneficiou toda a população, e sim apenas uma pequena parcela dela, em especial os novos comerciantes que chegavam ao Brasil." (SHIGUNOV NETO, 2015, p. 67)

$\mathrm{O}$ projeto educacional proposto por D. João
VI pretendia unificar a instrução pública no Brasil. Assim com o objetivo de organizar a instrução pública brasileira o General Francisco de Borja Garção Stockler elaborou sua proposta

fundamentada nos princípios educacionais de Condorcet, propunha que a instrução pública fosse oferecida em quatro graus de ensino: o ensino primário, que destinava a fornecer os conhecimentos indispensáveis a qualquer homem, independentemente de sua posição social ou profissão. Esse ensino seria ministrado pelos "pedagogos" e as escolas eram denominadas de "pedagogias"; o segundo grau de ensino, que é o que se conhece hoje por ensino profissionalizante, pois acrescia aos conhecimentos adquiridos no grau anterior conhecimentos indispensáveis aos agricultores, aos artistas, aos operários e aos comerciantes. As aulas eram ministradas pelos "instrutores" e as escolas eram denominadas de "institutos"; o terceiro grau de ensino era constituído pelos conhecimentos científicos, que serviam de base ao estudo aprofundado da literatura, das ciências e de toda espécie de erudição, ou seja, era uma espécie de preparação para o ensino superior. As aulas eram ministradas pelos "professores" e as escolas, denominadas de "liceus"; o último grau de ensino destinava-se ao ensino das ciências abstratas e ao estudo das ciências morais e políticas. As aulas eram ministradas pelos "lentes" e as escolas eram conhecidas por "academia"; é o que denomina-se hoje de ensino superior. (SHIGUNOV NETO, 2015, p.71)

Em 1820, com a chegada de notícias sobre a Revolução Liberal Portuguesa de 1820, D. João VI teve que retornar para Portugal, desta forma deixando a administração do Brasil aos cuidados de seu filho D. Pedro I. (SHIGUNOV NETO, 2015)

Assim, durante o período compreendido entre a partida de D. João VI e a proclamação da Independência, as questões políticas foram o centro das atenções da nação brasileira e de seus governantes, ficando as questões relacionadas à instrução pública relegadas ao esquecimento. (SHIGUNOV NETO, 2015, p. 72)

O período imperial da história brasileira iniciouse no ano de 1822 , quando D. Pedro I proclama a independência e outorga a primeira Constituição do Brasil em 1824, na qual se estabelecia que a educação primária seria gratuita para todos os cidadãos no país. De acordo com Nascimento $(2007$, p. 197) ele acrescenta "em 1827, uma lei determinou a criação de uma escola de primeiras letras em cada cidade, o que não chegou a ser cumprido" assim também acentua que nem todos teriam acesso a esta educação, sendo deixado de lado os escravos e o orçamento não supririam as necessidades. Sendo assim Aranha (2006) nos oferece mais um ponto relevante quando se analisa a Educação Brasileira e suas rupturas.

O golpe de misericórdia que prejudicou de vez a educação brasileira veio, no entanto, de uma emenda à Constituição, o Ato Adicional de 1834. Essa reforma descentralizou o ensino, atribuindo à Coroa a função de promover e regulamentar o ensino superior, enquanto às províncias (futuros estados) 
foram destinadas a escola elementar e a secundária. Desse modo, a educação da elite ficou a cargo do poder central e a do povo, confiada às províncias. (ARANHA, 2006, p. 382.)

De acordo com Shigunov Neto (2015) vemos que a situação da instrução pública - primária, secundária e superior -, no período que antecede a Constituição de 1823, era de extrema precariedade, expondo uma grande distância entre os

ideais pregados pelos liberais e a realidade, pois, nas poucas províncias em que existia instrução pública, esta era ineficiente e insuficiente para atender à demanda escolar, o que acabava por gerar um acréscimo gradativo no número de analfabetos e crianças em idade escolar fora das escolas. (SHIGUNOV NETO, 2015, p. 75)

Como características do ensino superior, Shigunov Neto (2015) nos apresenta, aproximadamente, as mesmas características e estrutura dos níveis primário e secundário, pois são cursos isolados, faltando vagas e profissionais qualificados, para ministrarem os cursos, faltavam organização e unidade, e eram baseados na literatura europeia. (SHIGUNOV NETO, 2015, p. 80)

De acordo com Shigunov Neto (2015) o Ato Adicional de 1834 também caracterizou-se por impulsionar o surgimento de instituições particulares de ensino secundário no Brasil. Assim, com a autonomia para legislarem sobre a instrução primária e secundária as províncias começaram a aprovar suas leis, tendo por base a Constituição Nacional de 1824. " Assim, uma das implicações do espírito liberal e descentralizador do Ato Adicional foi a omissão completa do Governo Geral em assuntos de educação popular fora da capital." (SHIGUNOV NETO, 2015, p. 81)

O Colégio Pedro II, fundado em 1837 no Rio de Janeiro, representa um marco educacional brasileiro, pois foi a instituição escolar de maior destaque no período imperial e a única a passar por dois momentos históricos notáveis e diferentes, o período imperial e o período republicano. O Colégio Pedro II teve sua origem do Colégio dos Órfãos de São Pedro, e que por decreto de 1837 foi transformado em Colégio Pedro II pelo então Regente Pedro de Araújo Lima. (SHIGUNOV NETO, 2015)

O objetivo do então ministro da educação Bernardo Pereira de Vasconcelos para com o Colégio Pedro II era o de criar um estabelecimento nacional de ensino nos moldes do Colégio de França, considerado um modelo educacional para a época. (SHIGUNOV NETO, 2015)

A instrução pública secundária no período compreendido entre 1837 e 1889 reduz-se ao ensino ministrado no Colégio Pedro II no Rio de Janeiro. O Colégio Pedro II, alvo dos maiores cuidados do Governo, não atuou, contudo, como padrão. Destinando-se precipuamente ao preparo de candidatos para os cursos superiores do Império, nortearam-se, de um modo geral, os demais estabelecimentos públicos e privados, pelas exigências mínimas consubstanciadas nos preparatórios para as matrículas nas Academias. (SHIGUNOV NETO, 2015, p. 83)

O Colégio Pedro II e os Liceus da Bahia e de Pernambuco, inspirados no modelo educacional francês, adotaram o sistema de estudos seriados, desenvolvidos em cursos regulares. Conforme Aranha (2006), lá também funcionava o originariamente Seminário de São Joaquim, criado em 1739.

O Colégio Pedro II fornecia o diploma de bacharel em letras, título necessário na época para cursar o nível superior. O colégio de Pedro II era frequentado pela aristocracia, onde era oferecido o melhor ensino, a melhor cultura, com o objetivo de formar as elites dirigentes deste país. (AGUIAR, 2013,p. 200)

Porém, com todas as modificações ocorrendo no campo da educação, vale destacar alguns aspectos que ainda continuavam no Brasil, se diferenciando dos que estavam acontecendo em outros países. Assim Aranha (2006, p. 384) destaca que a tendência de criar escolas religiosas no Brasil ou América Portuguesa eram opostas do resto do mundo, no século XIX, onde a laicização já se tornava frequente.

Shigunov Neto (2015) relata que rodeado por modificações e aliado ao processo de transformação social e econômica, e política, com a intensificação da propaganda republicana, que reaparece na cena política do país com a fundação do Clube Republicano. Entre os anos de 1885 e 1888 a crise do regime monárquico aumenta, em contrapartida, cresce o movimento republicano, o abolicionismo, e consequentemente o fortalecimento do exército com a Guerra do Paraguai (1865-1870), a crise do trabalho escravo e sua mudança para o trabalho livre.

\footnotetext{
Todas essas transformações evidenciaram um desnível muito grande entre as bases materiais da sociedade brasileira e a estrutura política até então instalada. O ápice desse momento histórico da sociedade brasileira foi a queda do Império, incapaz de adaptar-se às novas exigências e satisfazer aos anseios de uma nova sociedade, e a instauração da República. O Decreto no 1, de 15 de novembro de 1989, proclamava provisoriamente e decretava como forma de governo do Brasil a República Federativa, estabelecendo as normas pelas quais se deveriam reger os Estados Federais. (SHIGUNOV NETO, 2015, p. 101)
}

Com isso Marcos Oliveira (2004) nos apresenta o quadro do ensino no Brasil ao fim do Império, questões sobre a escola, quantidade de alunos, projetos entre outros

Ao final do Império, o quadro geral do ensino era o seguinte: poucas escolas primárias (com 250 mil alunos para um país com cerca de 14 milhões de habitantes, dos quais $85 \%$ eram analfabetos), liceus provinciais nas capitais, colégios particulares nas principais cidades, alguns cursos normais e os cursos superiores que forjavam o projeto elitista (para formação de administradores, 
políticos, jornalistas e advogados), que acabou se transformando num elemento poderoso de unificação ideológica da política imperial. (OLIVEIRA, 2004, p. 949)

A partir destas análises conseguimos refletir e evidenciar as rupturas que ocorreram na educação, desde a Educação da América Portuguesa, no Império do Brasil e a atual República Brasileira, onde a princípio a Educação jesuíta possuía um importante papel na formação do "homem" e através de métodos e estratégias citados por Silva (2014) conseguiu se ter na América Portuguesa o primeiro modelo de Educação onde visavam o pensamento e a conduta. Por mais que sua educação fosse voltada para a religião, o método jesuíta era embasado de conhecimento e estudos e Shirley Silva et al. (2014) ressalta também a importância que se dava aos professores e como estes deveriam agir.

Quando o Marquês de Pombal expulsa os Jesuítas encontramos a primeira ruptura na Educação do Brasil, onde um modelo de educação que já estava implantado e utilizado há mais de um século foi substituído e pela primeira vez como encargo do Estado. Marcos Oliveira (2004) destaca ainda, que Pombal voltava a educação para o comércio e não mais para uma formação apenas intelectual, com a substituição dos professores jesuítas e em seu lugar professores leigos do Estado que assumiram a tarefa de ensinar, destacado por Silva et al. (2014) como um momento trágico para a educação.

Até hoje temos colégios católicos em muitos lugares, e possuem um alto padrão tanto com os profissionais quanto para os alunos, "No Brasil, as Instituições de Educação Superior (IES) ligadas à Companhia de Jesus destacam-se pela qualidade acadêmica e visão humanística." (PORTAL JESUITAS BRASIL, 2019), ficando assim claro sua relevância e mesmo que depois de tanto tempo eles ainda tiveram forças para se reerguerem e continuar fazendo parte da organização educacional do Brasil, através da Rede Jesuíta de Educação que

é responsável por 17 escolas, colégios e creches, que reúnem mais de 31 mil alunos e quase 2 mil educadores. A Companhia de Jesus mantém ainda seis faculdades e universidades, além de atuar fortemente na área de Educação Popular, por meio de várias iniciativas, como Centro Santa Fé, Projeto OCA (Oficinas Culturais Anchieta), CAC (Centro Alternativo de Cultura) e Fundação Fé e Alegria, que atua em 14 estados, atendendo a mais de 10 mil crianças, adolescentes e jovens. (PORTAL JESUITAS BRASIL, 2019)

\section{Considerações finais}

Com este trabalho observou-se que a Companhia de Jesus teve um papel importante na Educação brasileira, influenciando em diversos aspectos, não só na metodologia mas também na formação de um professor, com destaque para o seu método, o Ratio
Studiorum que era composto por normas e hoje em dia podemos comparar com a atual LDB, considerando que ambos os documentos foram elaborados com objetivos voltados para a formação humana, assim pode-se ver a importância dada para a educação e o nível de elaboração de suas propostas, comparando-se também com o PPP (Projeto Político Pedagógico) como um documento norteador.

Assim a Companhia dos Jesuítas, representando a Igreja, e estando a frente da educação na América Portuguesa por mais de 200 anos trouxe grandes mudanças, principalmente para os colonos, que puderam de fato ter condições de educação adequada, mesmo que para os índios, que restava apenas a catequese, não eram privados da educação ou de uma base já que toda a estrutura de um novo sistema estava sendo formada. Assim pode-se observar que este ensino era baseado no humanismo.

Mesmo o Marquês de Pombal tentando reestruturar a educação, com influências iluministas, a partir das aulas régias, sua ação tinha a finalidade de comercialização das grandes descobertas que ocorriam na América Portuguesa com a sua riqueza, com isso o processo educacional torna-se frágil, pois diferente da educação jesuítica que possuía profissionais capacitados e preparados, a educação do Projeto Pombalino apresentava uma grande defasagem quanto a experiência e formação dos seus profissionais e ainda por não terem o auxílio de um método como era o Ratio Studiorum para os Jesuítas. O modelo de Educação proposto pelo Marquês Pombal pode ser considerado como um retrocesso na educação, onde ela ficou sob a égide do Estado, porém sem grandes recursos ou estratégias para sua aplicabilidade, e depois disto observa-se também a ruptura deste período Pombalino com a vinda da família real ao Brasil em 1808 levando a educação para um novo cenário.

Com o passar do tempo, medidas para a educação foram tomadas mediante as grandes demandas do Império Português para formar funcionários para atender as necessidades burocráticas do Estado. Até os dias atuais pode-se perceber como esta interferência teve influência em toda educação brasileira que, apesar dos ajustes e propostas não encontramos uma educação de fato que consiga suprir todas as demandas da sociedade, o que nos faz pensar como que esta estrutura educacional estaria hoje, caso os jesuítas estivessem à frente da educação? E conseguissem expor todos seus projetos e concretizá-los para a melhoria da Educação Brasileira?

Entende-se que o desenvolvimento da educação não é igual em todos os lugares do mundo. As sociedades possuem e adquirem características e singularidades que as tornam únicas e, a partir disso, pensam e organizam seus sistemas educacionais, assim levando em conta seus diferentes aspectos sociais, culturais e políticos. 
O próprio termo "educação" carrega em si inúmeros significados e, nesse sentido, é de grande importância pensar como tal conceito foi criado e desenvolvido ao longo do tempo na Educação brasileira.

A partir de alguns pontos pode-se analisar como a educação foi pensada no passado e no presente, a contribuição de cada época distinta. Levando um olhar reflexivo sobre os fenômenos educacionais, o papel da escola, a forma como os saberes são motivados e ensinados e os que permaneceram e que sofreram rupturas nos sistemas educativos.

Destacando-se a influência da Igreja Católica, que conseguiu através dos Jesuítas passar seus ensinamentos com propriedade e eficácia ao elaborar, projetos e documentos norteadores e de grande importância até hoje, observa-se também a educação tomando novos rumos, com a chegada de Marquês de Pombal, onde a Educação passou por um momento de transformação inspirada em pensamentos do Iluminismo, ao buscar o progresso científico, colocando o Estado como responsável pela Educação.

E ainda, as ações promovidas por D. João VI, grande parte de seus projetos se mantêm de pé até hoje sendo memoráveis, símbolos do nosso país. Passamos por D. Pedro I onde a gratuidade da educação primária é marcada, apesar de não ter atingido a proposta da legislação constitucional, e por fim, com D. Pedro II que tornou o colégio, que recebeu o seu nome em homenagem, como modelo do Brasil e até hoje possui um alto padrão, e então se tem o fim do império, que vem revelar como o Brasil se encontra frente às rupturas destas passagens da educação.

$\mathrm{Na}$ verdade, não se pode afirmar que um projeto de educação é melhor que o outro, todos tiveram seus pontos positivos e negativos, porém o processo educacional seria mais coeso no momento das transições com a identificação dos aspectos que de fato deveriam ser substituídos e/ou aperfeiçoados, não existindo a necessidade de mudanças drásticas e sim uma melhoria significativa para a educação do Brasil.

\section{Notas}

1. LDBEN - Lei de Diretrizes e Bases da Educação Nacional.

\section{Referências}

AGUIAR, Maria Marlene Miranda. 500 Anos de Políticas Públicas Educacionais deFinanciamento no Brasil. Revista de Educação DomAlberto, n. 4, v. 1, ago./dez. 2013. Disponível em: https://consolidareeducacional.com. br/wp-content/uploads/sites/41/2017/07/500-Anos-de-Pol\%C3\%ADticas$\mathrm{P} \% \mathrm{C} 3 \%$ BAblicas-Educacionais-de-Financiamento-no-Brasil.pdf. Acesso em 09 de ago. 2020

ALMEIDA, Wilson R. A. A educação jesuítica no Brasil e o seu legado para a educação da atualidade. Revista Grifos, v. 23, n. 36/37, p. 117-126, 2014. Disponível em: https://bell.unochapeco.edu.br/revistas/index.php/grifos/ article/view/2540. Acesso em 09 ago. 2019.
ARANHA, Maria Lúcia de Arruda. História da educação e da pedagogia: Geral e Brasil. São Paulo: Moderna, 2006. Disponível em: https:// fbnovas.edu.br/site/wp-content/uploads/2019/02/Acervo $\% 20 \mathrm{em} \% 20 \mathrm{PDF} /$ Hist $\%$ C3\%B3ria $\% 20$ da $\% 20$ Educa $\%$ C3\%A7\%C3\%A3o\%20e\%20da $\% 20$ Pedagogia.pdf. Acesso em 31 jul. 2020.

BOAVENTURA, Edivaldo M. A educação brasileira no período Joanino. In: BOAVENTURA, Edivaldo M. A construção da universidade baiana: objetivos, missões e afrodescendência. Salvador: EDUFBA, p. 129141, 2009. Disponível em: http://books.scielo.org/id/4r/pdf/boaventura9788523208936-08.pdf. Acesso em 10 de ago. 2020.

CALEGARI, Ricardo P. Os 210 anos de pedagogia jesuíta no Brasil. Anais do Seminário Internacional de Educação Superior, p. 1-10, 2014. Disponível em: https://www.uniso.br/publicacoes/anais eletronicos/2014/5 es_memoria/03.pdf. Acesso em: 09 ago. 2019.

CASIMIRO, Ana Palmira Bittencourt Santos. Pensamentos fundadores na educação religiosa do Brasil Colônia. Navegando na História da Educação Brasileira. Campinas-SP: Graf. FE: HISTEDBR, 2006. Disponível em: https://www.lage.fe.unicamp.br/pf-lage/ana palmira casimiro2 artigo.pdf. Acesso em 15 de jul. 2020

FALCON, Francisco José Calazans. Iluminismo. 4. ed. São Paulo: Ática, 1994.

HILSDORF, Maria Lucia Spedo. História da educação brasileira: leituras. Cengage Learning Editores, 2003. Disponível em: https://integrada. minhabiblioteca.com.br/\#/books/9788522114023/cfi/5!/4/2@100:0.00. Acesso em 11 nov. 2020.

KLEIN, Luiz Fernando. Trajetória da educação jesuítica no Brasil. pedagogiaignaciana.com, 2016. Disponível em: http://pedagogiaignaciana. com/GetFile.ashx?IdDocumento=3026. Acesso 11 nov. 2020 .

NASCIMENTO, Maria Isabel Moura. Instituições escolares no Brasil colonial e imperial. 2007. Disponível em: http://ri.uepg.br:8080/riuepg/ bitstream/handle/123456789/706/ARTIGO_Institui\%c3\%a7\%c3\%b5esEsc olaresBrasil.pdf?sequence $=1$. Acesso em 08 de nov. 2020 .

OLIVEIRA, Leilson B.; LIMA NETO, Osvaldo B.; LEMOS, Sebastiana M. A. Um Estudo sobre a Pedagogia Jesuítica: o Ratio Studiorum e um breve Comparativo ao Projeto Político Pedagógico. Rev.Mult. Psic., 2018, vol.12, n.41, p.627-636. ISSN: 1981-1179. Disponível em: https://idonline. emnuvens.com.br/id/article/view/1246/1818. Acesso em 15 nov. 2019.

OLIVEIRA, Marcos Marques de. As origens da educação no Brasil da hegemonia católica às primeiras tentativas de organização do ensino. Ensaio: avaliação e políticas públicas em educação, v. 12, n. 45, p. 945-958, 2004. Disponível em: https:/www.scielo.br/pdf/ensaio/v12n45/v12n45a03.pdf. Acesso em 20 de ago. 2019.

PORTAL JESUITAS BRASIL. Apostolado educacional. 2019. Disponível em: https://www.jesuitasbrasil.org.br/educacao/. Acesso em 12 set. 2020.

RIBEIRO, Paulo Rennes Marçal. História da educação escolar no Brasil: notas para uma reflexão. Paidéia (Ribeirão Preto), n. 4, p. 15-30, 1993. Disponível em: $\quad$ https://www.scielo.br/scielo.php?script=sci arttext\&pid=S0103863X1993000100003. Acesso em 10 de ago. 2020.

ROSA, Maria Carlota. Acerca das duas primeiras descrições missionárias de língua geral. Amerindia. Revue d'Ethnolinguistique Amerindienne, v. 19 , n. 20 , p. $273-184$, 1995. Disponível em: http://etnolinguistica.wdfiles. com/local--files/artigo\%3Arosa-1995/rosa_1994.pdf. Acesso em 06 de ago. 2020 .

SANTOS FILHO, José Maximino dos et al. A POLÍTICA DOS JESUÍTAS E A EDUCAÇ̃̃O ILUMINISTA DO MARQUÊS DE POMBAL. Encontro Internacional de Formação de Professores e Fórum Permanente de Inovação Educacional, v. 8, n. 1, 2015. Disponível em: https://eventos.set. edu.br/enfope/article/view/1207/109. Acesso em 09 jan. 2021

SÁ, Bruno Vivas; Coelho, Maria Thereza Ávila Dantas. A influência da igreja católica na educação brasileira: da companhia de jesus ao ensino superior. Trabalhos Apresentados em Eventos (PPGEISU) Disponível: $\quad$ https://repositorio.ufba.br/ri/bitstream/ri/9252/1/A\%20 INFLU\%c3\%8aNCIA \%20DA \%20IGREJA \%20CAT\%c3\%93LICA \%20 NA $\% 20$ EDUCA $\%$ c3\%87\%c3\%830\%20BRASILEIRA.pdf. Acesso em 15 de nov. 2019. 
SHIGUNOV NETO, Alexandre. História da educação brasileira: do período colonial ao predomínio das políticas educacionais neoliberais São Paulo: Salta, 2015. Disponível em: https://integrada.minhabiblioteca.com. br/\#/books/9788597007688/. Acesso em: 21 Jan 2021

SILVA, Shirley M. da et al. A Educação Jesuítica no Brasil Colônia e sua Herança Contemporânea. Anais do III Congresso Nacional de Educação. Disponível em: https://www.editorarealize.com.br/editora/anais/ conedu/2016/TRABALHO EV056 MD1 SA1 ID2919 17082016171627. pdf. Acesso em 02 de ago. 2019.

VITO, R. V.; MELO, J. J. P. Considerações sobre a Ratio studiorum e a lei de diretrizes e bases da educação nacional $n^{\circ}$ 9394/96: a organização da educação em questão. EDUCERE - Revista da Educação, Umuarama, v. 15, n. 2, p. 263-278, jul./dez. 2015. Disponivel em: https://revistas.unipar.br/ index.php/educere/article/view/5624. Acesso em 10 nov. 2020. 